\title{
RHINOLOGY
}

\section{How to predict the outcome of septorhinoplasty? A normative study of ROE and FROI-17 scores}

\section{Prevedere l'esito della settorinoplastica? Valori di riferimento per i questionari ROE e FROI-17}

\author{
Michaela Plath ${ }^{1}$, Matthias Sand ${ }^{2}$, Carlo Cavaliere ${ }^{3}$, Peter K. Plinkert ${ }^{1}$, Ingo Baumann ${ }^{1}$, Karim Zaoui ${ }^{1}$ \\ ${ }^{1}$ Department of Otorhinolaryngology, Head and Neck Surgery, University Hospital Heidelberg, Heidelberg, Germany; ${ }^{2}$ GESIS- \\ Leibniz-Institute for the Social Sciences, Mannheim, Germany; ${ }^{3}$ Department of Oral and Maxillofacial Sciences, Sapienza University \\ of Rome, Italy
}

\section{SUMMARY}

Objective. Normative values of patient-reported outcome instruments are needed to identify good candidates for rhinoplasty. Rhinoplasty Outcome Evaluation (ROE) and Functional Rhinoplasty Outcome Inventory-17 (FROI-17) are disease-specific questionnaires that evaluate quality of life in patients undergoing rhinoplasty.

Methods. The reference cohort contained 1,000 participants, selected from a non-probability panel. Normative ROE and FROI-17 scores from this reference cohort were compared with ROE and FROI-17 scores from a patient cohort before $(n=104)$ and $6(n=55)$ and 12 months $(\mathrm{n}=32)$ after septorhinoplasty.

Results. Mean FROI-17 scores $( \pm$ SD) were: overall score, $20.8 \pm 17$; nasal symptoms, $16.8 \pm 7$; general symptoms, $24.8 \pm 22$; and self-confidence, $16.4 \pm 21$. The ROE total score was $73.1 \pm 16$. Normative values differed significantly from the preoperative ROE and FROI-17 scores of septorhinoplasty patients $(\mathrm{p}<0.01)$. Except for the FROI-17 general score at 12 months postoperatively $(\mathrm{p}=0.004)$, there were no significant differences between normative ROE/FROI-17 and septorhinoplasty scores postoperatively, indicating that they returned to normalcy.

Conclusions. Normative scores for ROE and FROI-17 provide a reference point from which to identify patients who are most likely to benefit from rhinoplasty.

KEY WORDS: normative score, patient-reported outcome measures, rhinoplasty outcome evaluation, functional rhinoplasty outcome inventory-17, rhinoplasty

\section{RIASSUNTO}

Obiettivo. L'identificazione dei valori di riferimento per i questionari di autovalutazione permette di selezionare $i$ candidati migliori per la rinoplastica. Il Rhinoplasty Outcome Evaluation (ROE) e il Functional Rhinoplasty Outcome Inventory-17 (FROI-17) sono questionari che valutano la qualità della vita dei pazienti sottoposti a rinoplastica.

Metodi. 1000 volontari sani sono stati reclutati come popolazione di riferimento. I valori standard del ROE e del FROI-17 sono stati poi confrontati con $i$ valori rilevati in un gruppo di pazienti prima dell'intervento di rinosettoplatica $(n=104)$ e dopo $6(n=55)$ e 12 mesi $(n=32)$.

Risultati. I valori medi del FROI-17 ( \pm SD) sono: punteggio totale 20,8 \pm 17 ; sintomi nasali 16,8 \pm 7 ; sintomi generali $24,8 \pm 22$; autostima $16,4 \pm 21$. Il punteggio totale del $\operatorname{ROE}$ è $73,1 \pm 16$. I valori standard si sono rivelati significativamente diversi dai valori del ROE e del FROI-17 dei pazienti pre-intervento $(p<0,01)$. Ad eccezione del punteggio totale del FROI-17 a 12 mesi $(p=0,004)$, non si sono evidenziate differenze significative tra $i$ valori standard e i punteggi dichiarati dai pazienti a 6 e a 12 mesi, a indicare il ritorno alla normalità.

Conclusioni. La standardizzazione del ROE e del FROI-17 è utile a identificare i pazienti con maggiori probabilità di beneficiare della rinoplastica.

PAROLE CHIAVE: standardizzazione dei questionari, questionari di autovalutazione dei pazienti, rhinoplasty outcome evaluation, functional rhinoplasty outcome inventory-17, rinoplastica
Received: December 2, 2020

Accepted: January 24, 2021

\section{Correspondence}

Karim Zaoui

Department of Otorhinolaryngology, Head and Neck Surgery, University Hospital Heidelberg, Ruprecht-Karls-University, Im Neuenheimer Feld 400, D-69120 Heidelberg, Germany

Tel. +49-(0)6221-56 39510

E-mail: karim.zaoui@med.uni-heidelberg.de

Funding

None.

Conflict of interest

The Authors declare no conflict of interest.

How to cite this article: Plath M, Sand M, Cavaliere C, et al. How to predict the outcome of septorhinoplasty? A normative study of ROE and FROI-17 scores. Acta Otorhinolaryngol Ital 2021;41:327-335. https://doi. org/10.14639/0392-100X-N1291

(c) Società Italiana di Otorinolaringoiatria e Chirurgia Cervico-Facciale

\section{(c) (1) $(2)$}

This is an open access article distributed in accordance with the CC-BY-NC-ND (Creative Commons Attribution-NonCommercial-NoDerivatives 4.0 International) license. The article can be used by giving appropriate credit and mentioning the license, but only for non-commercial purposes and only in the original version. For further information: https:// creativecommons.org/licenses/by-nc-nd/4.0/deed.en 


\section{Introduction}

Rhinoplasty is a popular cosmetic surgical procedure and was the fifth most common operation in $2013^{1}$. Facial symmetry and proportions are important determinants of attractiveness ${ }^{2}$, and the nose is a vital part of a person's appearance and identity ${ }^{3}$. Male gender, young age, minimal deformities, and unrealistic expectations of the surgical results all reduce satisfaction after facial cosmetic surgery ${ }^{4}$. Furthermore, patients with body dysmorphic disorders are almost never fully satisfied with rhinoplasty results ${ }^{5}$. Patient-reported outcome measures are relevant because patient satisfaction and improved quality of life (QoL) are predominant factors for rhinosurgical success ${ }^{3,6}$. Many studies have described that patients benefit physically and psychologically from rhinoplasty and that QoL increases after rhinoplasty ${ }^{7}$. Patient-reported outcome measures in rhinoplasty research are very diverse ${ }^{8-10}$. The Rhinoplasty Outcome Evaluation (ROE) is the most used QoL questionnaire $(70.6 \%)^{3}$, and focuses on aesthetic outcomes ${ }^{11}$, while the Functional Rhinoplasty Outcome Inventory 17 (FROI-17) evaluates functional and aesthetic outcomes ${ }^{8}$. There are still no normative scores for the ROE and FROI-17 questionnaires. It is not yet known how the QoL of patients undergoing septorhinoplasty compares with that of a control population. This limits our ability to determine the impact of septorhinoplasty on individuals.

Normative scores of the generic and internationally approved instrument, the short form survey 36 (SF-36), for German participants were published in $2005^{12}$. In 2017, normative scores were also published for the breast surgery-specific and validated patient-reported outcome questionnaire, BREAST-Q ${ }^{13}$. Both are useful interpretive tools for clinicians and researchers.

The main aim of our study was to provide the first normative values for the ROE and FROI-17 questionnaires as a decision-making tool after septorhinoplasty by performing a systematic prospective study on 1,000 healthy participants and comparing these normative values with ROE and FROI-17 scores of septorhinoplasty patients before and after surgery.

\section{Materials and methods}

\section{Patient cohort}

1,000 German individuals were recruited via a non-probabilistic online panel. The subset of this panel used for this study was quoted to relevant population distributions of the German Microcensus (an annual 1\% probability sample of the German population) ${ }^{14}$. Relevant parameters were age, gender, region and education. Migration was also taken into account but not quoted for. Participants consented to their data being collected.

Data from the reference cohort $(\mathrm{n}=1,000)$ were compared with data from a patient cohort before septorhinoplasty $(\mathrm{n}=104)$ and $6(\mathrm{n}=55 / 54)$ and 12 months $(\mathrm{n}=32 / 31)$ after surgery at Department of Ear, Nose and Throat, Head and Neck Surgery, University of Heidelberg, Germany between January 2010 and March 2011.

The Ethics Committee of the Medical Faculty at the University of Heidelberg granted permission to conduct the study (Project No. 409/2006) according to the Declaration of Helsinki on biomedical research involving human subjects. Informed consent was obtained from all patients. Patients were evaluated during an outpatient examination (usually one day before the surgery). They were asked to fill out questionnaires including FROI-17 and ROE. Surgery was performed by one of the authors. With the request to answer the questionnaire again, patients were contacted by mail at 6 months and 1 year after surgery. One hundred and four septorhinoplasty patients were enrolled in this study (53 women, 51 men). After 6 months, 52.4\% remained (55 FROI-17/54 ROE answers), and after 12 months 30.3\% (31 FROI-17/32 ROE answers) remained. Since this follow-up required a high degree of compliance, patients who did not respond were contacted by telephone. Due to the young and mobile septorhinoplasty patient collective, interest in participation in the study was decreased.

\section{Recruitment process}

The reference cohort $(\mathrm{n}=1,000)$ was recruited by September 2018 using the Respondi panel, an international organization for standardisation (ISO)-certified online access panel for market and social science research. Due to the nature of a cohort derived from the general public, that sample size was decided on to ensure a small sampling error and smaller confidence intervals, since the occurrence of participants with low (or high) QoL-measures was expected to be less pronounced than in the clinical cohort. The programming of the questionnaire, quota conditions and quota sizes were programmed by Respondi. Participants were divided into groups in the panel based on the master data information. Before finalising the questionnaire, an internal test run was conducted. On the first day of recruitment, only 200 participants were invited for a first data check after which other participants received reporting access. Sociodemographic questions were asked first. Study participants answered 59 questions, including two disease-specific questionnaires (FROI-17 and ROE), by online access within a mean time of approximately $7 \mathrm{~min}$ and $16 \mathrm{sec}$ (arithmetic mean). Raw data were cleansed and converted into a labeled SPSS dataset before checking that questions were complete and rel- 
evant quotas were distributed. Test groups were screened to make sure the correct questions had been asked. Statistical analysis was conducted by GESIS (Leibniz Institute for Social Sciences).

\section{Disease-specific questionnaires (ROE and FROI-17)}

ROE and FROI-17 are validated and reliable disease-specific instruments for measuring QoL after septorhinoplasty. The ROE has six questions, each one with five answers, from zero (worst) to four (best). The sum of the scores is then converted into a percentage with a lower score indicating less satisfaction. The FROI-17 includes 17 items. Responses are rated zero (no problem) to five (worst possible). The overall score is then converted into a percentage with a lower score indicating more satisfaction ${ }^{7,15}$.

\section{Statistical analysis}

Data were analysed using the statistical software R (version 3.4.1). Absolute, relative and joint distributions were created for the indices and sociodemographic variables. The five indices (ROE, FROI-17, and the three FROI-17 sub-indices) were tested for independence of sociodemographic characteristics using the Pearson's chi-squared test. A significant p-value (e.g. $\alpha \leq 0.05$ ) rejected the null hypothesis that variables are independently distributed, and supported a relationship (not necessarily linear) between variables. In this case, $p$ values were calculated via Monte Carlo statistic ${ }^{16}$. Correlation between the FROI indices and the ROE were also assessed.

The (linear) influence of sociodemographic variables was tested via generalised regression. For metric variables, the published coefficients relate to the slope by which a value increases. For non-metric variables (most sociodemographics), model.matrix is used. The coefficients show the increment of increase, when deviating from baseline (first level of a variable; e.g., if male gender is the baseline, the coefficient for the FROI overall index increases by 3.3 if the participant is female). Aside from the coefficients, residual standard errors, Student's t-statistics and $\mathrm{p}$ values are also reported.

The calculated indices of the reference cohort were compared with those in the patient cohort before and 6 and 12 months after septorhinoplasty. Comparisons were made using a Student's t-test for unequal variances, and $p$ values are reported. If the $\mathrm{p}$ value was not significant, the null hypothesis that there is no difference between the variables was rejected.

\section{Results}

The reference cohort of 1,000 participants included 500 males and 500 females with an average age of $44.3 \pm 14.2$ years (Tab. I). Since participants belong to a non-probabil-
Table I. Demographic characteristics of the study population $(n=1000)$.

\begin{tabular}{|c|c|}
\hline Characteristic & $\begin{array}{l}\text { Reference cohort } \\
\quad(n=1000)\end{array}$ \\
\hline Age (years) & $\begin{array}{c}44.3 \pm 14.2 \\
\text { (range:18-69) }\end{array}$ \\
\hline \multicolumn{2}{|l|}{ Gender } \\
\hline Male & $500(50 \%)$ \\
\hline Female & $500(50 \%)$ \\
\hline \multicolumn{2}{|l|}{ Marital status } \\
\hline Single & $411(41.1 \%)$ \\
\hline Married & $424(42.4 \%)$ \\
\hline Separated/divorced & $138(13.8 \%)$ \\
\hline Widowed & $27(2.7 \%)$ \\
\hline \multicolumn{2}{|l|}{ Residence (state) } \\
\hline Baden-Wurttemberg & $71(7.1 \%)$ \\
\hline Bavaria & $137(13.7 \%)$ \\
\hline Berlin & $27(2.7 \%)$ \\
\hline Brandenburg & $25(2.5 \%)$ \\
\hline Bremen & $18(1.8 \%)$ \\
\hline Hamburg & $57(5.7 \%)$ \\
\hline Hesse & $91(9.1 \%)$ \\
\hline Mecklenburg-Vorpommern & $18(1.8 \%)$ \\
\hline Lower Saxony & $93(9.3 \%)$ \\
\hline North Rhine-Westphalia & $161(16.1 \%)$ \\
\hline Rhineland & $82(8.2 \%)$ \\
\hline Saarland & $33(3.3 \%)$ \\
\hline Saxony & $52(5.2 \%)$ \\
\hline Saxony-Anhalt & $28(2.8 \%)$ \\
\hline Schleswig-Holstein & $67(6.7 \%)$ \\
\hline Thuringia & $40(4.0 \%)$ \\
\hline \multicolumn{2}{|l|}{ Country of birth } \\
\hline Germany & $958(95.8 \%)$ \\
\hline EU country & $19(1.9 \%)$ \\
\hline Non-EU country & $23(2.3 \%)$ \\
\hline \multicolumn{2}{|l|}{ Graduation } \\
\hline No degree & $10(10 \%)$ \\
\hline Certificate of Secondary Education & $300(30 \%)$ \\
\hline $\begin{array}{l}\text { General Certificate } \\
\text { of Secondary Education }\end{array}$ & $340(34 \%)$ \\
\hline High school diploma & $350(35 \%)$ \\
\hline \multicolumn{2}{|l|}{ Employment } \\
\hline On leave/temporarily released & $24(2.4 \%)$ \\
\hline Not working or no longer working & $292(29.2 \%)$ \\
\hline Employed occasionally or by the hour & $71(7.1 \%)$ \\
\hline Part-time employment & $154(15.4 \%)$ \\
\hline Full-time employment & $459(45.9 \%)$ \\
\hline Household member & $2.5 \pm 2.4$ \\
\hline
\end{tabular}


istic open access panel with quoted parameters and a fixed sample size, the response rate is not reported. Participants were sampled from an existing (opt-in) access panel until a particular quota was filled.

We also recruited a cohort of patients undergoing septorhinoplasty in our department. At the time of surgery patients were on average $28.8 \pm 11.5$ years old. The demographic and clinical data are shown in Table II.

The normative ROE and FROI-17 scores differed significantly from the ROE and FROE-17 scores of patients before septorhinoplasty $(\mathrm{p}<0.01)$. There were no significant differences between the normative ROE and FROI-17 scores and those of septorhinoplasty patients at 6 and 12 months after surgery to the reference cohort, except for the FROI-17 general score at 12 months after surgery $(\mathrm{p}=0.004$; Tab. III). However, the substantial loss of participants especially after 12 months, may have impacted the estimator's variance. Such an increase in variance could also explain the lack of significance.

Concerning the impact of sociodemographic factors on the

Table II. Demographic characteristics of septorhinoplasty patients before, 6 and 12 months after surgery.

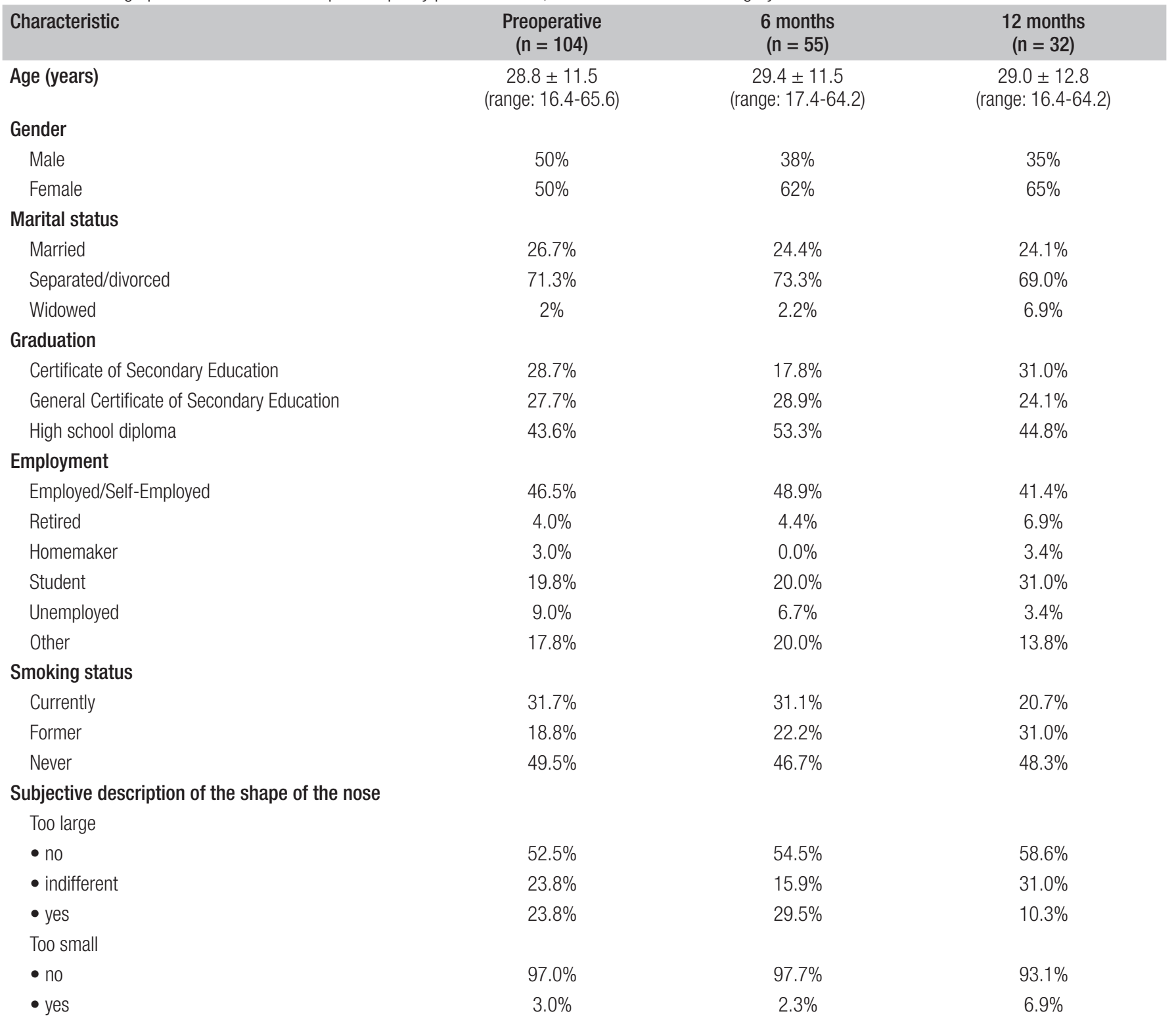


Table II. Demographic characteristics of septorhinoplasty patients before, 6 and 12 months after surgery (follows).

\begin{tabular}{|c|c|c|c|}
\hline Characteristic & $\begin{array}{l}\text { Preoperative } \\
(\mathrm{n}=104)\end{array}$ & $\begin{array}{c}6 \text { months } \\
(\mathrm{n}=55)\end{array}$ & $\begin{array}{c}12 \text { months } \\
(\mathrm{n}=32)\end{array}$ \\
\hline \multicolumn{4}{|l|}{ Too long } \\
\hline - no & $70.3 \%$ & $75 \%$ & $72.4 \%$ \\
\hline - indifferent & $13.9 \%$ & $11.4 \%$ & $13.8 \%$ \\
\hline - yes & $15.8 \%$ & $13.6 \%$ & $13.8 \%$ \\
\hline \multicolumn{4}{|l|}{ Too short } \\
\hline - no & $95.1 \%$ & $97.0 \%$ & $97.0 \%$ \\
\hline - yes & $4.9 \%$ & $3.0 \%$ & $3.0 \%$ \\
\hline \multicolumn{4}{|l|}{ Too wide } \\
\hline - no & $64.4 \%$ & $79.6 \%$ & \\
\hline - indifferent & $18.8 \%$ & $9.1 \%$ & NA \\
\hline - yes & $16.8 \%$ & $11.3 \%$ & \\
\hline \multicolumn{4}{|l|}{ Crooked nose } \\
\hline - no & $43.6 \%$ & $43.6 \%$ & $43.6 \%$ \\
\hline - indifferent & $17.8 \%$ & $17.8 \%$ & $17.8 \%$ \\
\hline - yes & $38.6 \%$ & $38.6 \%$ & $38.6 \%$ \\
\hline \multicolumn{4}{|l|}{ Nasal bumps } \\
\hline - no & $40.6 \%$ & $40.6 \%$ & \\
\hline - indifferent & $14.9 \%$ & $14.9 \%$ & NA \\
\hline - yes & $44.6 \%$ & $44.6 \%$ & \\
\hline \multicolumn{4}{|c|}{ Nose tip too clumsy } \\
\hline • no & $74.3 \%$ & $74.3 \%$ & \\
\hline - indifferent & $11.9 \%$ & $11.9 \%$ & NA \\
\hline - yes & $13.9 \%$ & $13.9 \%$ & \\
\hline \multicolumn{4}{|c|}{ Nose tip too pinted } \\
\hline • no & $91.1 \%$ & & \\
\hline - indifferent & $5.0 \%$ & NA & NA \\
\hline - yes & $4.0 \%$ & & \\
\hline \multicolumn{4}{|l|}{ Nose tip bent } \\
\hline$\bullet$ no & $73.3 \%$ & $72.2 \%$ & \\
\hline • indifferent & $11.9 \%$ & $20.9 \%$ & NA \\
\hline - yes & $14.9 \%$ & $7.0 \%$ & \\
\hline
\end{tabular}

functional and aesthetic septorhinoplasty outcomes, age and female gender significantly affected the FROI overall and self-confidence scores $(\mathrm{p}<0.05)$, whereas no variables influenced the nasal symptom score ( $p>0.05$; Fig. 1$)$. Female participants $(\mathrm{n}=500)$ had higher FROI-17 scores (Fig. 1B) and lower ROE (Fig. 2B) scores, and the overall (22.4 vs 19.1), general (27 vs 22.7), and self-confidence (19.8vs 13.1) FROI-17 scores were significantly different between males and females ( $<<0.01$; Fig. 1B, Tab. IV).

Only age significantly influenced the FROI-17 (Fig. 1A) and ROE (Fig. 2A) scores $(\mathrm{p}<0.01)$. Participants older than 50 years had lower FROI-17 scores (negative linear relation) and higher ROE scores (positive linear rela- tion) $(\mathrm{p}<0.01)$. Marital status, residence state, education level and employment status had no effect on the ROE or FROI-17 scores. A migration background only affected the FROI overall score $(\mathrm{p}=0.037)$.

For most variables, the chi-square test after Pearson showed that the null hypothesis that variables are independently distributed cannot be rejected, except for the joint distribution of ROE and age as well as FROI confidence and age.

\section{Discussion}

Measuring QoL after plastic surgery has become more important in recent years ${ }^{7,8,11}$. In a systematic literature search 
Table III. Comparison of ROE and FROI-17 scores between the reference cohort and the patient cohort before and 6 and 12 months after septorhinoplasty.

\begin{tabular}{|c|c|c|c|c|c|c|c|c|c|c|c|}
\hline \multirow{2}{*}{$\begin{array}{l}\text { Disease-specific } \\
\text { questionnaires } \\
\text { FROI-17 Index }\end{array}$} & \multicolumn{2}{|c|}{$\begin{array}{l}\text { Reference cohort } \\
\qquad(\mathrm{n}=1000)\end{array}$} & \multicolumn{2}{|c|}{$\begin{array}{c}\text { Preoperative } \\
(\mathrm{n}=102 \mathrm{~F} / 101 \mathrm{R})\end{array}$} & \multirow[t]{2}{*}{$p$-value } & \multicolumn{2}{|c|}{$\begin{array}{c}6 \text { months } \\
(n=55 \mathrm{~F} / 54 \mathrm{R})\end{array}$} & \multirow[t]{2}{*}{$\mathrm{p}$-value } & \multicolumn{2}{|c|}{$\begin{array}{c}12 \text { months } \\
(\mathrm{n}=31 \mathrm{~F} / 32 \mathrm{R})\end{array}$} & \multirow[t]{2}{*}{$p$-value } \\
\hline & Mean & SD & Mean & SD & & Mean & SD & & Mean & SD & \\
\hline Overall score & 20.8 & 17.1 & 32.3 & 17.5 & $<0.01$ & 18.3 & 15.0 & 0.3 & 17.2 & 16.4 & 0.25 \\
\hline Nasal score & 16.8 & 16.6 & 31.7 & 17.0 & $<0.01$ & 16.9 & 14.1 & 1.0 & 17.2 & 15.0 & 0.88 \\
\hline General score & 24.8 & 21.5 & 33.0 & 22.8 & $<0.01$ & 20.2 & 19.3 & 0.1 & 14.9 & 17.3 & $<0.01$ \\
\hline Self-confidence & 16.4 & 21.1 & 31.5 & 27.2 & $<0.01$ & 14.4 & 17.5 & 0.5 & 13.8 & 19.3 & 0.45 \\
\hline ROE Index & 73.1 & 15.9 & 39.7 & 15.1 & $<0.01$ & 72.4 & 18.6 & 0.8 & 68.5 & 17.8 & 0.16 \\
\hline
\end{tabular}

Higher ROE scores and lower FROI-17 scores indicate higher levels of satisfaction. Values are presented as mean \pm standard deviation. F: FROI-17; R: ROE.

with the terms "Rhinoplasty" and "Quality of Life" using PubMed/MEDLINE, Google Scholar and Cochrane databases, the authors concluded that the ROE was the most

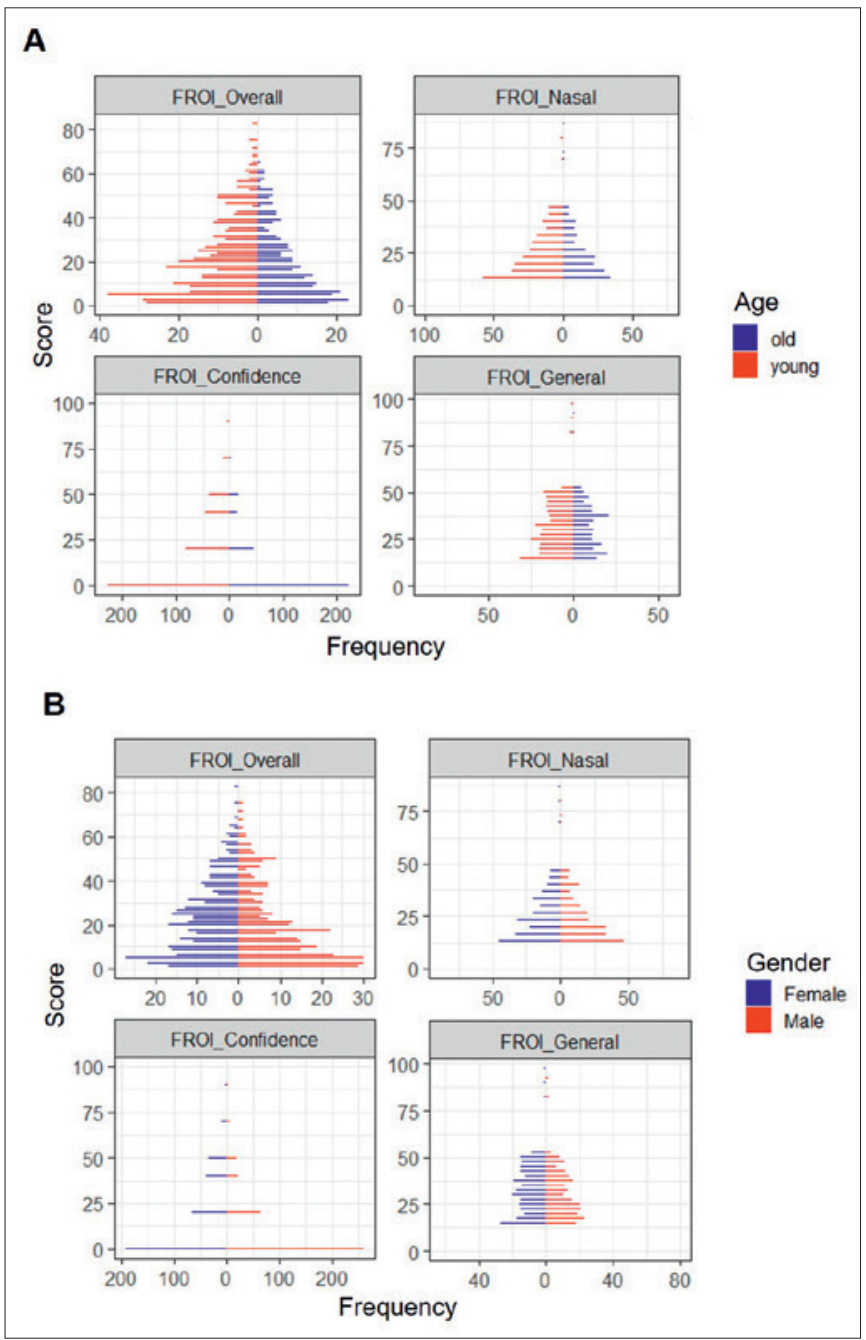

Figure 1. Forest plots showing the association between FROI-17 scores and age (A) and gender (B). The questionnaire score is plotted on the $y$-axis, and the frequency of score responses on the $\mathrm{x}$-axis. frequently used QoL questionnaire (70.6\%) by focusing on prospective study design, a significant cohort size (at least 50 patients) and a follow-up period of at least 6 months after rhinoplasty. They further reported that the measurement of both satisfaction of appearance and physical function of the nose makes the ROE score, FROI-17 and the novel Standardized Cosmetics and Health Nasal Outcomes Survey (SCHNOS) more eligible for functional and cosmetic rhinoplasty than QoL questionnaires with general functional and/or aesthetic components ${ }^{3}$. Since septorhinoplasty addresses functional and aesthetic impairments of the nose ${ }^{8}$, we specially selected the ROE and the FROI-17 as validated patient-reported outcome measures (PROMs) and not generic instruments (e.g. Short-Form Health Survey (SF-36) questionnaire ${ }^{17}$ or non-rhinoplasty-specific questionnaires (e.g. FACE-Q) ${ }^{9}$.

Rhinoplasty belongs to aesthetic surgeries with low levels of satisfaction ${ }^{18}$; therefore, identifying patients who are most likely to benefit from the surgery is fundamental for a successful outcome. Identifying patients who can benefit most from rhinoplasty could be simplified by comparing the ROE and FROI-17 scores with normative values by predicting which results will be satisfactory. In addition, rhinoplasty outcomes could be compared between the old and new federal states in Germany as well between Ger-

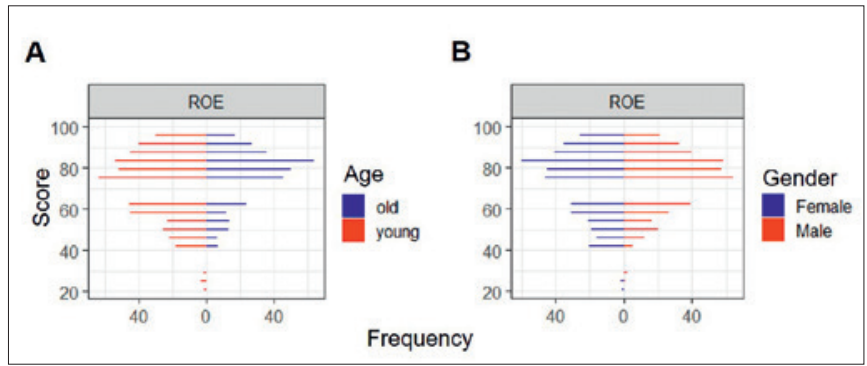

Figure 2. Forest plots showing the association between ROE scores and age $(\mathrm{A})$ and gender (B). The questionnaire score is plotted on the $y$-axis, and the frequency of score responses on the $\mathrm{X}$-axis. 
Table IV. Normative ROE and FROI-17 scores from the reference cohort $(n=1000)$.

\begin{tabular}{lccccc}
$\begin{array}{l}\text { Disease-specific } \\
\text { questionnaires }\end{array}$ & $\begin{array}{c}\text { All } \\
(\mathbf{n}=\mathbf{1 0 0 0})\end{array}$ & $\begin{array}{c}\text { Female } \\
(\mathbf{n}=\mathbf{5 0 0})\end{array}$ & $\begin{array}{c}\text { Male } \\
(\mathbf{n}=\mathbf{5 0 0})\end{array}$ & $\begin{array}{c}<\mathbf{5 0} \text { years } \\
(\mathbf{n}=\mathbf{6 1 9})\end{array}$ & $\begin{array}{c}>50 \text { years } \\
(\mathbf{n}=\mathbf{3 8 1})\end{array}$ \\
$\begin{array}{l}\text { FROI-17 } \\
\text { Overall score }\end{array}$ & & & & & \\
Nasal symptoms & $20.8 \pm 17.1$ & $22.4 \pm 17.1$ & $19.1 \pm 17.0$ & $22.0 \pm 17.6$ & $18.7 \pm 16.1$ \\
General symptoms & $16.8 \pm 16.6$ & $17.3 \pm 16.8$ & $16.3 \pm 16.4$ & $17.7 \pm 16.9$ & $15.3 \pm 16.0$ \\
Self confidence & $24.8 \pm 21.5$ & $27 \pm 21.6$ & $22.7 \pm 21.3$ & $25.9 \pm 22$ & $23.1 \pm 20.7$ \\
R0E & $16.4 \pm 21.1$ & $19.8 \pm 22.6$ & $13.1 \pm 19.0$ & $19.3 \pm 22.7$ & $11.7 \pm 17.4$ \\
\hline
\end{tabular}

Values are presented as mean \pm standard deviation.

many and other industrialised countries, such as the United States. Alsaraf et al. performed a prospective pilot study of 78 patients treated in three cosmetic surgery centres in the United States and concluded that patient-reported outcome measures are useful to assess cosmetic facial plastic surgery outcomes and provide the surgeon with a more objective means of comparing treatment options ${ }^{11}$. Selfadministered questionnaires can be completed quickly and are less expansive, but can be influenced by response shift bias ${ }^{19}$.

In this study, the FROI-17 scores (overall score, nasal symptoms, general symptoms, and self-confidence) and ROE index revealed significantly more functional impairment before rhinoplasty than after rhinoplasty. Herruer et al. (2018) showed that patients seeking rhinoplasty have more distress associated with self-consciousness of appearance than the general unconcerned population ${ }^{20}$. In the present study, we did not find significant differences in aesthetic and functional burden between the reference cohort and postoperative patient cohort, except for the FROI-17 general score which was significantly lower in the patient cohort 12 months after rhinoplasty (14.9 vs 24.8; $\mathrm{p}=0.004)$. These findings suggest that rhinoplasty has general benefits. Oedema following rhinoplasty can mask the final result for up to 12 months and can adversely affect patient satisfaction ${ }^{7,11,21}$. Although we lost almost $70 \%$ of our septorhinoplasty patients to follow-up at 12 months, we have decided to include these data precisely to take into account the long times obtaining a restitutio ad integrum. The limit of this comparison is the consistent dropout at 12 months that can lead to an increase in the estimator's variance. However, the aim of this study was not to compare groups, but rather establish normative values for the ROE and FROI-17 questionnaires in a European reference cohort as a fundamental help for rhinosurgeons in qualitatively monitoring their own performance and treatment results. Reasons for this dropout rate might be the lack of participants' interest due to the setting for the clinical cohort, since it may be expected that interest in such a study may decrease after surgery was received. In addition, sociodemographic characteristics such as the participants' age or mobility may also play a role.

We observed that age has a significant influence on the functional and aesthetic outcomes of rhinoplasty. Participants older than 50 years had lower FROI-17 scores and higher ROE scores, indicating higher levels of satisfaction. This finding is supported by the results of Litner et al. ${ }^{22}$ and Bulut et al. ${ }^{7}$, who argued that mental impairment affects the physical health of young, healthy individuals. Older people are more accepting of who they are and how they look, and thus are better able to adapt to their new facial appearance and functional disabilities. Contrary to our findings, previous studies reported that younger patients were more satisfied with their QoL following rhinoplasty than patients older than 35-40 years. This may be because patients become less satisfied with their facial appearance as they age, e.g., because of facial lines, loss of cheek fullness, and bags under the eyes ${ }^{23}$. However, it is difficult to compare age-related findings between studies because the age limits are different. In our opinion, being older than 40 does not fall under the definition of old.

Female gender also affected the normative FROI-17 general and self-confidence scores of the reference cohort. Female participants had higher FROI-17 scores and lower ROE scores, indicating lower levels of satisfaction. This may be because females pay more attention to their facial appearance. In addition, their self-image and body satisfaction are negatively affected by unrealistic beauty standards and demands to hide outer imperfections imposed by social media ${ }^{24}$. Global QoL instruments like the SF-36 have shown that women have poorer health scores than men across eight domains ${ }^{25}$. Rohrich et al. (2003) also argued that male patients have less understanding of their health - in this case nose deformity - than women do ${ }^{26}$.

A weakness of our study is that the sample was a non-probabilistic quota sample, so that the data is more suited to descriptive analysis; inference cannot be calculated. Therefore, we have to assume that FROI and ROE scores are 
independently distributed between those that opt-in and those that do not. We assumed that the decision to participate in the Respondi panel was not correlated to anything that may affect the FROI and ROE scores. We considered this reference cohort to be a "healthy" cohort in contrast to our patient cohort of individuals undergoing rhinoplastic surgery. Thus, the medical history of facial trauma or nasal surgery was not queried. We observed differences in all index scores between these cohorts. Another limitation of our study is the homogeneity of the European reference cohort presented here, which may not be comparable to a more diverse or ethnic patient population. Minimizing this demographic influence, a proportion of persons with a migration background was included in our participant recruitment. Thus, future research needs to utilise Caucasian and non-Caucasian patient populations to compare patient satisfaction and QoL in the context of race.

However, our study has a number of strengths. We used a well-established study design. In addition, we had a large sample size of 1,000 participants that was representative of industrial countries. The present study suggests that the ROE and FROI-17 questionnaires are reliable and sensitive disease-specific instruments to measure QoL in septorhinoplasty patients and healthy individuals. Even though almost $70 \%$ of patients were lost to 12 -month follow-up, the study can be useful for rhinoplasty surgeons to evaluate the perception of surgical results in their patients and compare them with normative values. Comparing ROE and FROI-17 scores with normative values explains any differences in scores better than simply comparing scores before and after surgery. Preoperative patients are not "normal" because they carry the physical and psychological burden of nasal deformity. The normative values reported herein can be used in future studies and may help the rhinoplastic surgeon make clinical decisions. These values can be used to compare surgical techniques, quantify positive effects and identify those patients who are most likely to benefit from surgery. They may also determine whether patients have returned to normalcy after septorhinoplasty.

\section{Conclusions}

Patient-reported outcome instruments play a key role in assessing QoL. We present the first normative scores for ROE and FROI-17, which should be of fundamental help to rhinoplastic surgeons and researchers. Using these values, we can now determine whether septorhinoplasty will be associated with a return to normalcy.

\section{Ethical considerations}

The Ethics Committee of the Medical Faculty at the University of Heidelberg granted permission to conduct the study (Project No. 409/2006) according to the Declaration of Helsinki on biomedical research involving human subjects.

\section{References}

1 Cosmetic surgery National Data Bank: statistics 2012. Aesthet Surg J 2013;33:1S-21S. https://doi.org/10.1177/1090820X13493905

2 Chatrath P, De Cordova J, Nouraei SA, et al. Objective assessment of facial asymmetry in rhinoplasty patients. Arch Facial Plast Surg 2007;9:184-187. https://doi.org/10.1001/archfaci.9.3.184

3 Wahmann MS, Bulut OC, Bran GM, et al. Systematic review of quality-of-life measurement after aesthetic rhinoplasty. Aesthetic Plast Surg 2018;42:1635-1647. https://doi.org/10.1007/s00266-018-1199-6

4 Herruer JM, Prins JB, van Heerbeek N, et al. Negative predictors for satisfaction in patients seeking facial cosmetic surgery: a systematic review. Plast Reconstr Surg 2015;135:1596-1605. https://doi. org/10.1097/PRS.0000000000001264

5 Jerome L. Body dysmorphic disorder: symptom or syndrome. Am J Psychiatry 1994;151:460-461; author reply 1-2. https://doi. org/10.1176/ajp.151.3.aj1513460

6 Klassen AF, Cano SJ, Scott A, et al. Measuring patient-reported outcomes in facial aesthetic patients: development of the FACE-Q. Facial Plast Surg 2010;26:303-309. https://doi.org/10.1055/s-0030-1262313

7 Bulut OC, Wallner F, Plinkert PK, et al. Quality of life after septorhinoplasty measured with the Functional Rhinoplasty Outcome Inventory 17 (FROI-17). Rhinology 2015;53:54-58. https://doi. org/10.4193/Rhin14.008

8 Bulut C, Wallner F, Plinkert PK, et al. Development and validation of the Functional Rhinoplasty Outcome Inventory 17 (FROI-17). Rhinology 2014;52:315-319. https://doi.org/10.4193/Rhin13.098

9 Schwitzer JA, Sher SR, Fan KL, et al. Assessing patient-reported satisfaction with appearance and quality of life following rhinoplasty using the FACE-Q Appraisal Scales. Plast Reconstr Surg 2015;135:830e837e. https://doi.org/10.1097/PRS.0000000000001159

10 Dizdar D, Bozan A, Dizdar SK, et al. Evaluation of nasal symptoms in septoplasty patients using SNOT-22. Acta Otorhinolaryngol Ital 2019;39:98-102. https://doi.org/10.14639/0392-100X-2061

11 Alsarraf R, Larrabee WF, Jr., Anderson S, et al. Measuring cosmetic facial plastic surgery outcomes: a pilot study. Arch Facial Plast Surg 2001;3:198-201. https://doi.org/10.1001/archfaci.3.3.198

12 Morfeld M, Bullinger M, Nantke J, et al. [The version 2.0 of the SF-36 Health Survey: results of a population-representative study]. Soz Praventivmed 2005;50:292-300. https://doi.org/10.1007/ s00038-005-4090-6

13 Mundy LR, Homa K, Klassen AF, et al. Breast cancer and reconstruction: normative data for interpreting the BREAST-Q. Plast Reconstr Surg 2017;139:1046e-1055e. https://doi.org/10.1097/ PRS.0000000000003241

14 Gabler SH-Z, Jürgen HP, Krebs D. Gewichtung in der Umfragepraxis. Springer VS Soziologie 1994:106 ff.

15 Bulut OC, Wallner F, Hohenberger R, et al. Quality of life after primary septorhinoplasty in deviated- and non-deviated nose measured with ROE, FROI-17 and SF-36. Rhinology 2017;55:75-80. https:// doi.org/10.4193/Rhin16.243 
16 Hope ACA. A simplified Monte Carlo significance test procedure. J R Stat Soc Series B Stat Methodol 1968;30:582-598. https://doi. org/10.1111/J.2517-6161.1968.TB00759.X

17 Ware JE, Jr., Sherbourne CD. The MOS 36-item shortform health survey (SF-36). I. Conceptual framework and item selection. Med Care 1992;30:473-483. https://doi. org/10.1097/00005650-199206000-00002

18 Freiberg A, Giguere D, Ross DC, et al. Are patients satisfied with results from residents performing aesthetic surgery? Plast Reconstr Surg 1997;100:1824-1831; discussion 1823-1833. https://doi. org/10.1097/00006534-199712000-00029

19 Rohs FR, Langone CA, Coleman RK. Response shift bias: a problem in evaluating nutrition training using self-report measures. J Nutr Educ 2001;33:165-170. https://doi.org/10.1016/s1499-4046(06)60187-5

20 Herruer JM, Prins JB, van Heerbeek N, et al. Does self-consciousness of appearance influence postoperative satisfaction in rhinoplasty? J Plast Reconstr Aesthet Surg 2018;71:79-84. https://doi.org/10.1016/j. bjps.2017.08.008

${ }^{21}$ Pavri S, Zhu VZ, Steinbacher DM. Postoperative edema resolution following rhinoplasty: a three-dimensional morphometric assessment.
Plast Reconstr Surg 2016;138:973e-979e. https://doi.org/10.1097/ PRS.0000000000002760

22 Litner JA, Rotenberg BW, Dennis M, et al. Impact of cosmetic facial surgery on satisfaction with appearance and quality of life. Arch Facial Plast Surg 2008;10:79-83. https://doi.org/10.1001/archfaci.10.2.79

23 Schwitzer JA, Albino FP, Mathis RK, et al. Assessing demographic differences in patient-perceived improvement in facial appearance and quality of life following rhinoplasty. Aesthet Surg J 2015;35:784793. https://doi.org/10.1093/asj/sjv066

24 Brown Z, Tiggemann M. Attractive celebrity and peer images on Instagram: effect on women's mood and body image. Body Image 2016;19:37-43. https://doi.org/10.1016/j.bodyim.2016.08.007

25 Emery CF, Frid DJ, Engebretson TO, et al. Gender differences in quality of life among cardiac patients. Psychosom Med 2004;66:190197. https://doi.org/10.1097/01.psy.0000116775.98593.f4

26 Rohrich RJ, Janis JE, Kenkel JM. Male rhinoplasty. Plast Reconstr Surg 2003;112:1071-1085; quiz 86. https://doi.org/10.1097/01. PRS.0000076201.75278.BB 